\title{
Os estudos musicais e a educação do ouvido'
}

Émile Jaques-Dalcroze, 1898

Inutilidade dos estudos de harmonia desprovidos da aquisição ou da prévia utilização da audição "interior" - Necessidade de cultivar as faculdades auditivas dos harmonistas - Natureza dos exercícios conhecidos como "desenvolvimento do ouvido" - Perigos da realização de estudos especializados e, particularmente, de estudos de piano não acompanhados por estudos gerais - O papel das faculdades táteis e motoras na educação musical — Sensibilidade para elaboração de exercícios específicos destinados a regular e desenvolver o temperamento.

Um dos preceitos favoritos dos mestres de harmonia é o seguinte: "Não se deve jamais utilizar o piano para construir e escrever as sucessóes de acordes". Fiel à tradição, apliquei-me em repetir esse axioma durante as minhas aulas, até o dia em que um dos meus alunos perguntou-me com ingenuidade: "Mas, senhor, por que eu dispensaria o piano, uma vez que sem ele eu não sou capaz de ouvir coisa alguma?". Subitamente começou a vibrar, dentro de mim, uma centelha de verdade. Compreendi que toda regra que não tenha sido forjada pela necessidade e através da observação direta da natureza é arbitrária e falsa, e a proibição da utilização do piano não teria o menor sentido, a não ser que ela fosse destinada a jovens dotados de uma audição interior ${ }^{2}$. As sensações táteis podem, em certa medida e em alguns casos, substituir as sensações auditivas:

I. JAQUES-DALCROZE. Les études musicales et l'éducation de l'oreille [ I 898]. Lausanne: Fœtisch, 1965. p. 9-12. Edição original de 1920.

Tradução: José Rafael Madureira e Luci Banks-Leite. Notas: José Rafael Madureira. Revisão técnica: Leda Maria Farah.

[N.E.] Agradecemos aos herdeiros de Jaques-Dalcroze e à Editora Hug Musikverlage, detentora dos direitos sobre a obra de Jaques-Dalcroze, pela cessão dos direitos do artigo aqui traduzido.

2. A ideia de uma "audição interior" (audition intérieure) ou "ouvido interior" (oreille intérieure) é um conceito-chave na obra de Jaques-Dalcroze. Para ele, a música, especialmente o estudo de harmonia, não se constitui como atividade aritmética, mas como um exercício de sensibilidade: "A criança não deve escutar apenas com os ouvidos, mas com todo o seu ser". (JAQUESDALCROZE. La musique et l'enfant [1912]. In: JAQUES-DALCROZE. Le rythme, la musique et I'éducation. Lausanne: Fœtisch, 1965. p. 48. "O objetivo do meu ensino é permitir que os meus alunos digam, ao final de seus estudos, não apenas eu sei, mas eu sinto" (JAQUES-DALCROZE. La rythmique, II. Lausanne: Jobin \& Cie, 1917. p. viii). 
conhecemos compositores que possuem faculdades auditivas incompletas, mas conseguem escrever interessantes obras, compostas, como se diz, no piano. Eles seguramente só puderam estudar harmonia, negligenciando a observação da lei suprema, pois seria impossível escrever com precisão as sucessóes de acordes sem dispor de um ouvido interior que lhes fornecesse o eco antecipado de suas ressonâncias. Ou uma coisa ou outra: ou é preciso compor com o auxílio do piano, se não dispusermos de um ouvido musical, ou é necessário dispensar o piano, se formos capazes de ouvir. Ao imporem aos seus alunos a obrigatoriedade de escrever as harmonias sem o amparo de um instrumento, os professores têm, portanto, como dever, despertar nos estudantes o sentido auditivo musical e desenvolver neles o sentimento melódico, tonal e harmônico com o auxílio de exercícios especiais. Existem exercícios desse gênero? Esses exercícios são ensinados nas escolas de música? Essas foram as perguntas que eu me fiz inicialmente e que me esforçava em solucionar, escavando nas bibliotecas e consultando os programas de ensino dos Conservatórios. A resposta foi: "não, não existem procedimentos pedagógicos destinados a reforçar as faculdades auditivas dos musicistas e não há nenhuma escola de música preocupada em analisar o papel dessas faculdades nos estudos musicais".

Entendamos com clareza: existem, com toda certeza, numerosos livros nos quais são prescritos muitos exercícios de leitura à primeira vista, de transposição, de escrita e, mesmo, de improvisação vocal. No entanto, todos eles podem ser realizados sem o auxílio da audição; os exercícios de leitura e improvisação podem ser realizados com o auxílio do sentido muscular e os exercícios de transposição e escrita, com o auxílio do sentido visual. Nenhum deles é diretamente dirigido ao ouvido e, todavia, é através do canal auditivo que as vibraçōes sonoras são registradas em nosso cérebro. Não seria insensato ensinar música sem se preocupar em diversificar, graduar e combinar, em todas as suas nuances, as escalas de sensaçôes que despertam em nossa alma os sentimentos musicais? Como é possível que o ensino atual de música não leve em consideração a qualidade principal que caracteriza o músico?

Apliquei-me, portanto, a inventar exercícios destinados a reconhecer a altura dos sons, a medir os intervalos, a escrutar os sons harmônicos, a individualizar as diversas notas dos acordes, a seguir os desenhos contrapontísticos das polifonias, a diferenciar as tonalidades, a analisar as relaçóes entre as sensações auditivas e as sensações vocais, a desenvolver as qualidades receptivas do ouvido e - graças a uma ginástica ${ }^{3}$ de um novo gênero destinada ao sistema nervoso a criar, entre o cérebro, o ouvido e a laringe, correntes necessárias para fazer do organismo, como um todo, algo que pudesse ser denominado ouvido interior.

3. Trata-se da Rítmica que, em I898, encontrava-se ainda em gestação. 
Ingenuamente eu imaginei que bastaria inventar esses exercícios para que eles fossem aplicados nas aulas especiais!...

Infelizmente, as dificuldades com as quais eu me deparei ao tentar construir um sistema destinado ao desenvolvimento auditivo não eram nada, comparadas àquilo que encontrei ao tentar introduzir esse sistema nos programas de ensino $o^{4}$. Os grandes argumentos contra sua introdução eram que o verdadeiro musicista deveria possuir naturalmente as qualidades necessárias ao exercício de sua arte; e que o estudo não poderia substituir os dons naturais ${ }^{5}$. Por outro lado, o tempo de estudos, já muito limitado, tornava impossível, ao que parece, atrapalhar os alunos com novos estudos que os impedissem de dedicarse aos exercícios de técnica para os dedos. Além disso, "os estudos instrumentais eram suficientes para formar um bom músico", etc., etc. Alguns desses argumentos eram aparentemente justos, e é evidente que somente deveriam consagrarse à arte musical os indivíduos particularmente dotados, isto é, aqueles que possuíssem, digamos, de modo natural, as qualidades necessárias de reconhecimento dos sons, tais como sensibilidade dos nervos e elevação dos sentimentos, sem as quais não existe um músico perfeito. Mas, enfim, o fato de que as aulas de instrumento estão repletas de indivíduos incapazes de ouvir ou de escutar música permite-nos constatar que os conservatórios admitem ser possível, mesmo aos que não são músicos natos, cantar ou tocar piano! Ora, qual a razão para ocupar-se unicamente da instrução dos dedos desses alunos, esquecendo-se de sua educação auditiva?

Em relação aos bons músicos, dedicados aos estudos de composição ou de direção orquestral, não é possível supor que exercícios cotidianos de discernimento dos graus de intensidade e altura dos sons; de análises sensoriais dos timbres e de suas combinações; de polifonias e harmonias em todos os graus da escala sonora pudessem tornar seus ouvidos ainda mais refinados e sua inteligência musical ainda mais flexível?

4. A dificuldade descrita neste trecho refere-se especialmente às negativas do Conservatório de Música de Genebra, onde ele iniciou a carreira como professor de música, aos 27 anos, assumindo a cadeira de Harmonia Teórica. A ideia de afastar as mesas e realizar com os alunos pequenos deslocamentos, circulando pela sala - de pés descalços - provocou um grande desconforto nos diretores do Conservatório, que proibiram a continuidade daquelas experiências que consideravam "invenções satânicas" (JAQUES-DALCROZE. Petite histoire de la rythmique. Le Rythme, n. 39, p. 5, [1935]) ou ainda "macaquices" (ibidem). Jaques-Dalcroze, todavia, deu continuidade às pesquisas numa saleta alugada às suas próprias expensas e contando com o apoio de alguns amigos, como o psicólogo suíço Edouard Claparède ( I 873- 1940), professor da Universidade de Genebra, que forneceu a Dalcroze os conceitos clínicos empregados na fundamentação teórica da Rítmica.

5. Dalcroze posicionou-se muito claramente na contramão de um ensino de música destinado unicamente aos "gênios". Por toda vida ele se empenhou em introduzir o ensino da Rítmica em todas as escolas públicas, convencido de que a música era um direito de todos os indivíduos. 
O estilo musical varia de acordo com o clima e a latitude e, por conseguinte, de acordo com os temperamentos impregnados pelos ambientes e resultantes, assim, das condiçôes de vida. As divergências de harmonia e movimento que caracterizam a música dos diferentes povos derivam, portanto, do estado nervoso e muscular de cada organismo, independentemente de suas faculdades auditivas. Nos estudos musicais, não seria conveniente dedicar uma atenção especial às faculdades motoras dos alunos; ao conjunto de reaçôes, impulsos, de pausas e recuos, de movimentos espontâneos e movimentos deliberados que constituem o temperamento? Muitas vezes fiquei surpreso ao observar a dificuldade das crianças pequenas para acompanhar, andando, uma música muito lenta; realizar paradas ou partidas bruscas, conforme o comando; descontrair seus membros, ao sentirem medo; orientar ou combinar seus movimentos de braços, quando lhes ensinamos os gestos de uma canção. Tanto tempo se passa entre a vontade de movimentar-se e a possibilidade de realizar esse movimento, que não é de espantar que tantas pequenas laringes sejam inábeis; tantas cordas vocais se apresentem pouco flexíveis e pouco precisas; tantas respirações sejam mal reguladas nos exercícios de canto e também na maneira de escandir e dividir o tempo e de emitir a nota no momento justo. Portanto, não apenas o ouvido e a voz da criança deveriam ser exercitados, mas também tudo aquilo que, em seu corpo, coopera com os movimentos ritmados, tudo aquilo que, músculos e nervos, vibra, contrai-se e descontrai-se sob a ação de impulsos naturais. Não seria, então, possível criar novos reflexos; empreender uma educação dos centros nervosos; acalmar os temperamentos agitados demais; regular os antagonismos e harmonizar as sinergias musculares; estabelecer comunicações mais diretas entre os sentidos e a mente, entre as sensações que provocam a inteligência e os sentimentos que recriam meios sensoriais de expressão?6 Todo pensamento é a interpretação de um ato. Uma vez que, até hoje, tem sido suficiente oferecer à mente a consciência do ritmo graças unicamente às experiências musculares da mão e dos dedos, não lhe comunicaríamos impressões muito mais intensas se fizéssemos colaborar o organismo inteiro em experiências que lhe despertassem a consciência tátil-motriz? Ponho-me a sonhar com uma educação musical na qual o próprio corpo desempenharia o papel de intermediário entre os sons e o pensamento e tornar-se-ia o instrumento direto de nossos sentimentos - em que as sensações do ouvido se tornariam mais

6. Para conquistar a desejada fluência de comunicação entre os canais receptores do ouvido e a resposta muscular, Jaques-Dalcroze criou o denominado hop musical, um sinal sonoro, rítmico ou harmônico destinado a manter o "corpo e a mente sob pressão" (JAQUES-DALCROZE. La musique et nous: notes sur notre double vie. Genève: Perret-Gentil, 1945. p. 159). O hop musical é um dos princípios mais eloquentes da Rítmica e deve ser empregado não apenas com instrumentos de percussão, mas, sobretudo, através das infinitas possibilidades rítmicas, melódicas e harmônicas do piano.

Pro-Posições, Campinas, v. 21, n. 1 (61), p. 219-224, jan./abr. 2010 
fortes, graças àquelas provocadas pelas múltiplas matérias suscetíveis de vibrar e ressoar em nós: a respiração dividindo os ritmos das frases e as dinâmicas musculares traduzindo as dinâmicas que ditam as emoções musicais. Assim, na escola, a criança não só aprenderia a cantar e a escutar com precisão e no compasso, mas aprenderia também a mover-se e a pensar de modo preciso e ritmicamente ${ }^{7}$. Começaríamos por regular o mecanismo do andar ${ }^{8}$, aliando os movimentos vocais aos gestos de todo o corpo. E isso seria, ao mesmo tempo, uma instrução para o ritmo e uma educação e pelo ritmo?.

Infelizmente, quando penso nas dificuldades que tenho atualmente para convencer os educadores musicais sobre a possibilidade de exercícios cujo objetivo seja ensinar a criança a escutar as sonoridades antes de executá-las e registrálas graficamente ${ }^{10}$ e a despertar o pensamento antes de empreender sua tradução, eu me pergunto: a educação dos centros motores será possível um dia? Os homens recusam toda proposta nova, quando certas tentativas anteriores lhes proporcionam alguma satisfação e suas mentes habituaram-se a não mais contestar a utilidade delas. Todo ato libertador com o qual consentem parece-lhes definitivo e imutável, e toda verdade futura parece-lhes hoje uma mentira. Todavia, o pensamento humano desenvolve-se pouco a pouco, apesar das resistências; as ideias esclarecem-se; os desejos afirmam-se; os atos multiplicam-se. Um dia, quem sabe, quando os pedagogos vierem a reconhecer universalmente a possibilidade de reforçar os diversos modos de sensibilidade por meio de procedimentos de adaptação, variação e substituição, a educação musical possa apoiar-se menos exclusivamente na análise e mais no despertar das sensaçôes

7. E, além disso: "Ao deixar a escola, um cidadão completo deve ser capaz de viver normalmente, mas não apenas isso, ele também deve ser capaz de sentir a vida com emoção". (JAQUESDALCROZE. L'école, la musique et la joie [1915]. In: JAQUES-DALCROZE. Le rythme, la musique et l'éducation. Lausanne: Fœtisch, 1965. p. 95).

8. Jaques-Dalcroze considerava o andar um metrônomo orgânico capaz de oferecer ao caminhante "um modelo perfeito de medida e divisão do tempo em partes iguais" (IAQUES-DALCROZE. L'initiation au rythme [1907]. In: JAQUES-DALCROZE. Le rythme, la musique et I'éducation. Lausanne: Fœtisch, 1965. p. 39). Desse modo, andar acabou constituindo-se fundamento central das lições de Rítmica, sem perder de vista que "o estudo do andar é apenas um ponto de partida" (ibidem).

9. Todo pensamento de Jaques-Dalcroze apoia-se sobre a ideia de uma educação destinada ao pleno domínio das faculdades rítmicas. Para ele: "O ritmo é o alicerce de todas as artes" (JAQUESDALCROZE. L'initiation au rythme [1907]. In: JAQUES-DALCROZE. Le rythme, la musique et I'éducation. Lausanne: Fœtisch, 1965. p. 40), em especial para a música, "uma arte rítmica por excelência” (JAQUES-DALCROZE. Définition de la rythmique [192I]. Le Rythme, n. 7, p. 4). Foi através das teorias de seu professor e amigo Mattis Lussy ( 1 828-1909) que ele chegou a essas conclusões.

10. Esta preocupação é bastante recorrente no pensamento de Jaques-Dalcroze: "Não seria estranho ensinar uma criança a escrever antes que ela soubesse falar?" (JAQUES-DALCROZE. Notes bariolées. Genève/Paris: Éditions Jeheber, 1948. p. 170). 
vitais e da consciência dos estados afetivos. Nesse dia, nascerão, por toda parte, métodos fundamentados na cultura da combinação das sensaçôes auditivas e táteis, e eu poderei desfrutar da silenciosa alegria daqueles que puderam proferir, em algum momento doloroso de suas vidas, o eterno "E pur si muove!". 